\title{
Cardioprotective effect of silicone built restraint device (ASD), for left ventricle remodeling in rat heart failure models
}

\author{
Kiganda Raymond Sembatya ${ }^{1}$, Wang Gang ${ }^{2}$, Naveed Muhammad ${ }^{2}$, Sufia Yasmeen ${ }^{2}$, and \\ Xiaohui Zhou ${ }^{2}$ \\ ${ }^{1}$ Affiliation not available \\ ${ }^{2}$ China Pharmaceutical University
}

May 7, 2020

\begin{abstract}
Purpose: This study was to assess the feasibility and cardio-protective effects of biocompatible silicon built restraint device (ASD) in rat's heart failure (HF) model. Background: Ventricle restraint therapy (VRT) is a well-established and promising approach for management of advanced-stage dilated HF. Previous VRT devices offer a subjective level of restraint to the dilated heart muscles. However, the impact of the restraint nature, mesh tubular design and biocompatibility of VRT devices is not well investigated. Method: The performance and compliance of ASD were determined in vitro by adopting a pneumatic drive and ball burst test. SD rats were grouped into four $(\mathrm{n}=24)$; control, HF, ASD+HF and CSD+HF groups, respectively. HF was induced by left anterior descending artery ligation in all groups except the control group. ASD and CSD devices were implanted in the heart of ASD+HF and CSD+HF groups respectively. Results: The functional and expansion ability of ASD was observed to be safer and suitable to attenuate ventricular remodeling. ASD treated rats showed normal heart rhythm which was validated by a smooth -ST and asymmetrical T-wave. Hemodynamic parameters, and systolic and diastolic functions improved in the $\mathrm{ASD}+\mathrm{HF}$ group and reduction in ventricular wall stress indicated reverse remodeling. Furthermore BNP values were reduced in ASD+HF group which confirmed ASD feasibility and reverse remodeling at a molecular level. ASD+HF group also showed no fibrosis thus proposing that ASD has its significant curative effects on the heart muscles. Conclusion: ASD was found to be a promising restraint therapy than the previously standard restraint therapies.
\end{abstract}

\section{Introduction}

Heart failure (HF) is a devastating disorder which brings about insufficient supply of blood to tissues and organs. A variety of factors may contribute to its pathogenesis like myocardial infarction (MI), valvular heart disease (VHD), cardiomyopathy and hypertension; these are marked by loss of myocytes, hypertrophy, and an increment in interstitial fibrosis ${ }^{1}$. HF is a global health problem and worsens as population ages ${ }^{2,3}$. During the last three decades, HF management by devices intervention significantly improved the survival rate ${ }^{4}$ and mean life expectancy in HF patients ${ }^{5}$. However, despite the advancement in therapies, the mortality rate (five years) of HF is nearly $50 \%$ worse than any type of cancers ${ }^{6}$.

Ventricle restraint therapy (VRT) is a well-established and promising therapy in managing advanced stage dilated HF. VRT devices are made up of biocompatible materials that offer a supportive role to the heart muscles without directly being in contact with blood ${ }^{7,8}$ They have been extensively investigated and also studied at different clinical phases ${ }^{9-11}$. However, despite the long investigation history, they haven't been used in clinical practice yet ${ }^{12,13}$. Recent research now focuses more on how to improve the nature of the restraint and biocompatibility of VRT to ensure reverse left ventricular (LV) remolding in the dilated heart ${ }^{8,14,15}$ LV remodeling occurs when neurohormonal, mechanical and most likely genetic factors modify ventricular shape, function and size ${ }^{1}$. Previous VRT devices offer a subjective level of restraint to the dilated heart 
muscles. However, the impact of the restraint nature, mesh tubular design and biocompatibility of VRT devices is not well investigated. Here, we modified VRT into exo-organoplasty intervention ${ }^{16}$, by designing a highly biocompatible silicon material ventricular attaching device; $\mathrm{ASD}^{17,18}$. The objective was to fill the ASD device tubules with a characteristic fluid and observe its restraint property. Furthermore, through this system pharmacological and biological agents can be delivered to the heart locally ${ }^{19,20}$ In this study, we have addressed the following important questions. Firstly, whether silicon built restraint device is feasible to attenuate ventricle remodeling in rats model of HF or not? Secondly, whether, hydraulic restraint is more promising therapy than former standard CSD restraint therapy or not?

Active hydraulic ventricular attaching support system (ASD) is a silicon built netlike device configured in a heart shape composed of flexible interconnected hollow tubes and covers both heart ventricles. It further contains two tubes at the top which are channeled outside the body after surgery; these link the ASD with a desired medical equipment ${ }^{16}$. The ASD system is an integrated treatment platform that integrates diagnosis, monitoring and therapeutic precision treatment in one system. It was designed to deliver ventricular restraint, pharmacological and biological therapeutic agents locally to heart muscles ${ }^{20}$. ASD tubes are filled with a fluid thereby exerting continues pressures on the dilated ventricles (Fig.I ) ${ }^{16,21}$

The Laplace law provides a basis for understanding ventricle remodeling. It suggests that ventricular wall stress can be reduced by three factors individually or in combination; that is, reduction in transmural pressure $(\mathrm{Ptm})$, cardiac chamber radius reduction, or increasing ventricular wall thickness ${ }^{22}$. The objective of ASD is to reduce ventricular wall stress through counter-pressure mechanismFig. 1 by exerting repetitive elastic force on the heart during the entire cardiac cycle, not just at end-diastole. Furthermore, the current study investigated the compliance and functional characteristics of ASD in-vitro. Here, the feasibility, biocompatibility and, nature of restraint of ASD device was studied in rat's HF model. We observed that ASD is feasible and highly biocompatible, thereby provided an adjustable and measurable ventricular hydraulic restraint (AMVR), thus it could be a promising therapy to treat dilated HF.

\section{Results}

\section{In vitro experiments}

\section{Functional characteristics of ASD}

Flow characteristics and pressure results of the ASD showed that afterload varied and the drive pressure regulated to obtain $6.6 \mathrm{~L} / \mathrm{min}$ flow rate (Fig. 2a). Drive pressure was changed and the afterload maintained as a constant in order to establish the flow rate generated by the device (Fig. 2b). These in vitro assessments represent ASD's performance for a completely failed ventricle.

\section{Compliance characteristics of the ASD}

The compliance experiments showed that ASD experiences multiaxial expansion under load. Low loading resistance is indicated by the initial shallow part of the curve which is then accompanied by transition to a higher load resistance until ASD failure. There's a shallow slope initially until $5 \mathrm{lbs}$ and $0.8 \mathrm{~cm}$ in deformation but as the load increased beyond 5lbs the curve steepened. At 46lbs ASD reached its load capacity and failed.

\section{(Figure 2c).}

Fig. 2d Plot representing the uniaxial compliance curve for ASD model directed towards the longitudinal and circumferential paths and multiaxial compliance curve for collation. The multiaxial compliance curve is 4 times larger than the uniaxial curves between $25 \%$ and $45 \%$ strain. However, the projected compliance curve is only 1.4 to 1.5 times greater than uniaxial compliance curves between $77 \%$ and $100 \%$ strain

\section{In vivo studies experiments}

\section{Electrocardiography}

All groups showed normal T-wave, no pathological Q-wave, isoelectric ST-segment and upright T-wave prior to any surgery fig $3(\mathrm{a} 1, \mathrm{~b} 1, \mathrm{c} 1, \mathrm{~d} 1)$. ST-segment got elevated early after 25 minutes of ligation in $\mathrm{HF}$, CSD $+\mathrm{HF}$ 
and ASD+HF groups fig 3(b2,c2,d2). HF group showed broad T-wave and smaller R-waves on $7^{\text {th }}$ and $15^{\text {th }}$ day fig 3(b3,b4), followed by pathological Q-waves and elevated ST-segment on the 30 ${ }^{\text {th }}$ day fig 3(b5). In the CSD + HF group T-wave started out smaller with a broader R-wave on the $7^{\text {th }}$ and $15^{\text {th }}$ day fig $3(\mathrm{c} 3, \mathrm{c} 4)$, but pathological Q-wave and elevated ST-segment emerged on the $30^{\text {th }}$ day fig $3(\mathrm{c} 5)$. However, in ASD+HF group T-wave was asymmetrical (upright) and R-wave deflected upward on $7^{\text {th }}$ and $15^{\text {th }}$ day fig $3(\mathrm{~d} 3, \mathrm{~d} 4)$, while on the $30^{\text {th }}$ day a smooth ST-segment (concave upward) and no pathological Q-wave was observed fig $3(\mathrm{~d} 5)$.

\section{Histopathology}

Masson's trichrome staining revealed the infarcted region of the collagen fibers and myocardial fibrosis regions were stained blue, while normal muscle fibers were stained red. The control group displayed no blue fibrotic area, HF group revealed a blue fibrotic area whereas the CSD+HF showed less blue fibrotic area at the border zone. The ASD+HF displayed a fibrotic free blue area (Fig. 4a). Furthermore, the quantification of fibrosis by ImageJ software also revealed similar observations (Fig. 4b)

\section{Hemodynamic parameters}

Figure 5 illustrates the nature of restraint level on LVSP, LVEDP and ventricle contractility assessment $\pm \mathrm{dP} /$ dtmax. As expected LVSP decreased significantly in HF group (89.74mmHg), but had no significant difference in ASD treated groups $(106.97 \mathrm{mmHg})$ as compared with control group. LVEDP level decreased in $\mathrm{ASD}+\mathrm{HF}$ group $(-1.92 \mathrm{mmHg})$ and showed a significant difference when compared to the control group (1.88mmHg), while in HF group it increased significantly (14.71mmHg). $\mathrm{dP} / \mathrm{dtmax}$ decreased in HF group $(\mathrm{p}<0.001)$, and increased in ASD treated group as compared with the control. Whereas $-\mathrm{dP} / \mathrm{dtmax}$ showed a high significant value in $\mathrm{HF}$ and $\mathrm{CSD}+\mathrm{HF}$ group $(\mathrm{p}<0.001)$ and no significant value in $\mathrm{ASD}+\mathrm{HF}$ treated rats was observed as compared with control group. The heart rate of ASD $+\mathrm{HF}$ group was also normalized as compared to the other treatment groups (Fig. 6b).

\section{Plasma BNP level}

Coronary artery ligation resulted from the increase in plasma BNP level in all groups. BNP level was evaluated at different stages during the treatment period. After placing the restraint device, plasma BNP levels gradually decreased in ASD $(51.983 \mu \mathrm{g} / \mathrm{L})$ and CSD $(59.462 \mu \mathrm{g} / \mathrm{L})$ treated rats, but didn't show any significant difference till the end of treatment period as compared with $\mathrm{HF}(70.125 \mu \mathrm{g} / \mathrm{L})$ group. However, by the end of the one-month treatment period, plasma BNP level significantly reduced in ASD+HF group $(\mathrm{p}<0.001)$ as compared to the HF group (Fig. 6a).

\section{Discussion}

Ventricular restraint therapeutic approach has shown promise in treatment and management of HF. Previous animals and human studies showed that CSD (Acorn CorCap) and Paracor HeartNet devices reverse the pathologic LV remodeling ${ }^{10,11}$. However, to recommence interest and further optimization of restraint therapy, it requires exhaustive understanding of the proper relationship of its restraint nature by optimizing its design and biocompatibility with the host heart. Previous studies of CSD and HeartNet used polypropylene and nitinol mesh to deliver standard restraint and reverse pathologic LV remodeling ${ }^{11,14}$.

In vitro studies by the use of a pneumatic drive showed the functional ability of ASD (Fig. 2). The unique characteristics of ASD device are; amplification volume, here the hydraulic stroke volume required to actuate the device is less than the consequent blood stroke volume. Due to energy conservation, the amplification volume is obtained by the necessity for greater drive pressure. The entire physiological afterload pressure and the stroke volume is equal to or less than that of the hydraulic drive pressure and the hydraulic stroke volume $^{23}$. Considering the normal flow rate and afterload pressure, the functional ability of the ASD is in the normal range which is vital for normal heart function (Fig. 2).

Compliance and device related fibrosis can also be affected by the heart shape and the nature in which ASD is fitted on the heart ${ }^{24}$. During mechanical loading, a comparative amount of intertwined movement within 
the ASD device can be observed. Exposure of ASD to multiaxial stress-strain study revealed expansion of the material between $12 \%$ and $22 \%$ as the material was exposed to a load up to about 5lbs per inch. The compliance value below the first loading allows the ASD device to fit closely to the surface of the heart during implantation and prohibits unnecessary load growth at end-diastole ${ }^{25}$. The external force applied by the heart during the time of diastole filling is somewhat less than 5lbs of the equivalent burst load ${ }^{26}$. Thus in actual application, the multiaxial extension of the ASD remains within the shallow part of the multiaxial stress-strain curve. Comformity in the longitudinal direction is fairly higher than in the circumferential direction (Fig.2c, d), hence the hypothesis that it promotes a chronic shape modification to the heart from a spherical to a more ellipsoid shape ${ }^{24,27}$. Multiaxial compliance values were observed to be lower than individual uniaxial compliance values signifying that confining stiffness of ASD in multiaxial or uniaxial loading is identical. However, strain to achieve that restraint is reliant on the loading direction.

Electrocardiography results in HF showed numerous anomalies (Fig.3). The most widely observed electrocardiographic anomalies are broad T-waves, small R-waves, deep Q-waves and ST-elevation which denote MI and dilated ventricles ${ }^{28}$. These were seen in HF group at days 7, 15 and 30 fig.3(b3-b5) and it was similarly noted in CSD treated rats at day 30 fig.3 (c5). ASD results reported progression in managing the dilated ventricles, ventricular relaxation and relieving HF symptoms. This is depicted by a smooth ST-segment, upright T-wave and normal Q-wave fig.3 $(\mathrm{d} 4, \mathrm{~d} 5)^{29,30}$. Therefore ASD device was postulated to be a safer and viable; furthermore, it mended cardiac performance without tampering with the myocardial structure and function.

Masson's trichrome staining is a widely used staining technique to distinguish collagen fibers from tissues and muscles. Myocardial tissue was stained with an acidic dye due to the presence of acidophilic cytoplasm. Collagen is easily penetrable by most dye because of its comparatively loose texture. However, the dye easily diffuses out allowing aniline blue to stain the collagen giving blue stained collagen fiber ${ }^{31}$. After LAD coronary artery ligation cardiac cell death takes place $^{32}$ and this was noticeable in HF group on day 30th. Left ventricle remodeling after LAD coronary artery ligation is categorized by hypertrophy and fibrotic changes to the heart ${ }^{33}$. Cardiac cell death leads to decrease in contractile force ${ }^{34}$. The CSD treated rats showed a blue stained border zone, which may be as a result to the reaction of the device placement to the heart. Whereas, SD rats treated with ASD device showed no blue stained areas (Fig. 4).

In the present study on day 30, the hemodynamic parameters were assessed and revealed that LVSP and $\mathrm{dp} /$ dtmax were decreased while LVEDP and $+\mathrm{dp} / \mathrm{dtmax}$ rose significantly in HF group as compared with the control. This indicated that both systolic and diastolic function in HF rats were impaired ${ }^{35}$. However, after treatment with ventricular restraint therapy, these pathological changes were restored. The result showed that hydraulic restraint (ASD+HF) led to superior and faster reduction in LVEDP as compared to standard restraint $(\mathrm{CSD}+\mathrm{HF})$. LVEDP reflects the compliance of the $\mathrm{LV}$ and its ability to receive blood from the left atrium during diastole ${ }^{36}$. Moreover, as the LV compliance decreases, the LVEDP rises, thereby initiating MI, ventricular dilatation and other cascade of $\mathrm{HF}^{37,38}$. Furthermore, LVSP and -dp/dtmax positively correlated with systolic function showing no significant difference as compared with the control after treatment with hydraulic restraint (Fig. 5) ${ }^{38,39}$. In summary, there was both systolic and diastolic dysfunction in HF group. Hydraulic restraint (ASD $+\mathrm{HF}$ ) had significant reduction in LV trans-myocardial pressure and ventricular wall stress which lead to superior reverse remodeling in comparison to standard restraint. Furthermore, ASD is feasible, biocompatible and didn't impair the hemodynamic parameters. It delivers hydraulic pressure to the ventricle throughout the cardiac cycle, not only at systolic but also at diastolic phase.

To further validate the functional and morphological changes, evaluation of the molecular markers of HF at different time intervals during the study was done (Figure 6). BNP levels were elevated with the progression of $\mathrm{HF}$ after coronary artery ligation. This is due to response to myocardial stretch and ventricle dilatation due to pressure or volume overload ${ }^{40}$. Till the middle of the treatment period, rats treated with ASD showed a slight decline in BNP level but not significantly different. However, at the end of treatment period, $\mathrm{ASD}+\mathrm{HF}$ group was significantly different from HF group. While CSD+HF group showed little significance as compared to HF group (Fig. 4). Nonetheless, our study demonstrated that hydraulic restraint provided 
by ASD device could lead to decreased BNP associated remolding. It might be one possible mechanism by which restraint applied through ASD prompts reverse remolding at a molecular level.

\section{Materials and Methods}

Sprague-Dawley (SD) male rats weighing 240-260g were acquired from College of Veterinary Medicine Yangzhou University (License \# SCXK (Su) 2015-2005, Yangzhou, China. Silk and polypropylene 6.0 sutures from Shanghai Jinhuan Chemical Co., Ltd, Shanghai, China. ECG and HX-300S ventilator from Chengdu technology \& market Co. LTD, Chengdu, China. The implantable and polyethylene catheters from Jiangxi Hongda Medical Equipment Group Co. LTD. Nanchang, Jiangxi, China. Biebrich scarlet-acid fuchsin and trichrome's staining kits from Beyotime Institute of Biotechnology, Haimen, China. Rat BNP ELISA kits from Shanghai Jinma Biological Co. LTD, Shanghai, China and finally CSD from Ethicon, Inc, Somerville, NJ USA. All procedures performed in studies involving animals were in accordance with the ethical standards of China Pharmaceutical University under the guidelines published by research council by the school of pharmacy, China pharmaceutical university and conforms to the guidelines for the care and use of laboratory animals published by US national institutes of Health (NIH, 1996).

\section{ASD fabrication}

A three-dimensional computer model of ASD (design as discussed in the introduction) was developed by using Rhinoceros 5.0 software. A blue wax model of ASD was then printed using 3D printing technology. The wax model was immersed in liquid silicon and dried in an oven at $50 @ \mathrm{C}$ for 3 hours. The wax was then melted from the ASD and silicon built ASD model was obtained ${ }^{1920}$. Leak testing using Cincinnati Test Systems Shanghai was finally performed to ensure no leakage or blockage in the ASD tubes.

\section{Animal model and ASD implantation}

24 SD male rats were obtained and randomly divided into four groups $(\mathrm{n}=6)$ Control group, HF group, $\mathrm{CSD}+\mathrm{HF}$ group and ASD+HF group respectively. HF model was then induced in all groups except the control group by left anterior descending (LAD) coronary artery ligation ${ }^{41}$. The method and process of ligation was performed as described by Sufia et.al and Naveed et.al with minor modifications ${ }^{19,20}$ After confirmation of $\mathrm{HF}$ in the rats, ASD was then implanted in the ASD+HF group. After steady-state baseline measurement, the ASD device was placed around the heart and sutured to the atrioventricular (AV) groove using prolene sutures (4-0) to cover both ventricles. The ASD device consists of two access lines connected with implantable catheters. The ASD portacath was channeled subcutaneously through the second intercostal space into the left anterior chest wall and extended outside the body through a $1 \mathrm{~cm}$ opening made in the skin at spinotrapezius. The sternum and portacath incision was then closed in layers ${ }^{19,20}$ Saline was instilled in $20 \mathrm{ml}$ increments into ASD tubules and electrocardiogram was monitored. AMVR was observed as the maximum pressure applied by the ASD to the epicardium through a constant volume of saline inside the ASD tubules. Maximum ASD pressure occurred at end diastole (the time point when the heart volume is large).

\section{CSD device implantation}

CSD was made of a polypropylene mesh and used as a positive control. CSD is a previously used restraint device to deliver standard restraint and has extensively been investigated in animal models as well as clinical trials. After the establishment of HF model, CSD device was implanted to the heart of CSD+HF group rats by wrapping it around the heart and secured to the AV groove. The electrocardiogram was monitored in accordance with guidelines used for placement of the Acorn CorCap cardiac support device (Acorn Cardiovascular, Inc, St Paul, Minn) such that LVEDP decreased by 5\% 10,42

\section{Functional and compliance characteristics of the ASD}

The performance of ASD was determined by using a pneumatic drive and a hydraulic drive was used for the implantable system. ASD was attached to a cylindrical flexible blood pump with a diastolic diameter of 6 $\mathrm{cm}$ and length of $5 \mathrm{~cm}$. This in-vitro study was performed by adopting the standard protocol of the previous 
study by Robert T. V. Kung et.al ${ }^{43}$. Compliance characteristics of the ASD were studied by adopting ball burst test (TMI Trading Shanghai Co., Ltd). The test was performed according to manufacturer instructions. Briefly, the pressure was applied by pressing a ball against the ASD tubules within a circular fixture. The ASD was determinedly held around the edge of this circular fixture through a pneumatic clamping device. The ASD distorts in multiaxial behavior when the pressure was applied. The load at which ASD fails to withstand the pressure was recorded by the transducer. Furthermore, uniaxial compliance curve for ASD model was plotted in the longitudinal and circumferential directions and multiaxial compliance curve was plotted for comparison.

\section{In-vivo experiments}

\section{Electrocardiography}

Animals were given $10 \%$ chloral hydrate as a sedative and were placed in supine posture on a surgical table. A BL-420 electrocardiogram was used to analyze ECG and signals were recorded on a personal computer. This electrocardiogram consists of four electrodes; red, black, yellow and green which were subcutaneously inserted into the animal's right upper limb, right lower limb, left upper limb and left lower limb respectively(according to manufacturer instruction). ECG was then recorded in series in all animals; before ligation and after ligation on days 7, 15 and 30 .

\section{Hemodynamic parameters}

For terminal studies (At day 30), all hemodynamic parameters like left ventricular systolic pressure (LVSP), left ventricular end diastolic pressure (LVEDP), dp/dtmax and -dp/dtmax were taken digitally at steady hemodynamic state and mean data was recorded at the end of the study. The heart rate was also measured using a BL-420 multi-channel physiological signal system on preoperative, postoperative and on days 7,15 and 30 . The mean data was then calculated at the end of the entire study period.

\section{Histopathology}

At the end of the observation period (30days), animals were subjected to euthanasia and extraction of the skin and muscle tissue till the neck region from the metasternum was carried out and the chest plate removed thereby exposing the heart. To avoid bleeding the aorta was laced with a silk suture and the heart was harvested. It was then filled with PBS (1:100) in order to remove any blood traces, fixed in $10 \%$ formalin and then incised into $5 \mu \mathrm{m}$ coronal sections. It was dehydrated with series of ascending ethanol before embedding it in paraffin. Collagen and muscle fibers were distinguished using Masson's trichrome staining. Weigert iron hematoxylin and Biebrich scarlet-acid fuchsin (plasma stain), phosphomolybdicphosphotungstic acid and aniline blue (fiber stain) was used on the $5 \mu \mathrm{m}$ sliced section of the heart to achieve trichrome staining ${ }^{44}$. The slides were finally observed under the photonic microscope with DFC420 camera fitted for histopathological changes. Images from the sections were digitally captured using image manager software and the level of fibrosis quantified by ImageJ software 4.7.0.

\section{BNP measurement}

ELISA kit was used to determine the B-type natriuretic peptide serum concentration using rats BNP kit following the manufacturer guidelines. Briefly, the animal's blood was obtained, centrifuged at 2000 $\mathrm{rpm} / \mathrm{min}$ for a couple of minutes at $4^{\circ} \mathrm{C}$ and the supernatant (blood plasma) obtained. The supernatant was then diluted 1:4 with a sample solution followed by addition of a stop solution and then the BNP was evaluated.

\section{Data Analysis}

Hemodynamic data is displayed as mean \pm SEM ( $\mathrm{n}=3$ ), one-way ANOVA followed by Dunnett's Multiple Comparison Test was used for statistical significance of other groups compared with control group. While BNP results are expressed as mean $\pm \mathrm{SD}$, Two-way ANOVA followed by Bonferroni test was used for statistical analysis compared with HF group. Where, ${ }^{*} \mathrm{p}=0.05,{ }^{* *} \mathrm{p}<0.01,{ }^{* * *} \mathrm{p}<0.001$.

\section{Conclusions}


ASD device is structurally composed of silicon a non-immunogenic and biocompatible material and provides promising restraint therapy as compared with previous standard restraint therapies. It improves cardiac function and reverses ventricular remodeling. Therefore, the future aim of our research is to deliver biological therapeutic agents to the heart though ASD and this initial feasibility study will provide a push to move forward. However more research is needed to assess whether pathologic remodeling persists after termination of restraint therapy or not and also assess the effect of ASD implantation on ventricular shape, size, and myocardial structure, as well as load-independent indices of ventricular functions over a longer treatment period.

Acknowledgements: This work was supported by the National Natural Science Foundation of China (Grant Nos. 30973003 \& 30901993) and Administration of TCM of Jiangsu province China (Grant No. LZ11093).

\section{Author Contributions:}

Conceptualization, Kiganda Raymond and Xiaohui Zhou; Methodology and software, Gang Wang; Validation, Kiganda Raymond, Muhammad Naveed and Gang Wang; Formal Analysis, Sufia Yasmeen; Data Curation, Ziwei Liu; Writing - Original Draft Preparation, Muhammad Naveed; Writing - Review \& Editing, Kiganda Raymond; Supervision, Project Administration and Funding Acquisition, Xiaohui Zhou.

Conflict of Interest: The authors declare no conflict of interest.

\section{References}

1. Jessup M, Brozena S. Heart Failure. New England Journal of Medicine [Internet]. 2003 May 15 [cited 2019 Jan 21];348(20):2007-2018. Available from: http://www.nejm.org/doi/abs/10.1056/NEJMra021498

2. Mozaffarian D, Benjamin EJ, Go AS, Arnett DK, Blaha MJ, Cushman M, de Ferranti S, Després JP, Fullerton HJ, Howard VJ, Huffman MD, Judd SE, Kissela BM, Lackland DT, Lichtman JH, Lisabeth LD, Liu S, Mackey RH, Matchar DB, McGuire DK, Mohler ER, Moy CS, Muntner P, Mussolino ME, Nasir K, Neumar RW, Nichol G, Palaniappan L, Pandey DK, Reeves MJ, Rodriguez CJ, Sorlie PD, Stein J, Towfighi A, Turan TN, Virani SS, Willey JZ, Woo D, Yeh RW, Turner MB, American Heart Association Statistics Committee and Stroke Statistics Subcommittee. Heart Disease and Stroke Statistics - 2015 Update. Circulation [Internet]. 2015 Jan 27 [cited 2019 Jan 21];131(4):e29-322. Available from: http://www.ncbi.nlm.nih.gov/pubmed/25520374 PMID: 25520374

3. Braunwald E. The war against heart failure: The Lancet lecture. The Lancet [Internet]. Elsevier Ltd; 2015;385(9970):812-824. Available from: http://dx.doi.org/10.1016/S0140-6736(14)61889-4 PMID: 25467564

4. Jhund PS, MacIntyre K, Simpson CR, Lewsey JD, Stewart S, Redpath A, Chalmers JWT, Capewell S, McMurray JJV. Long-Term Trends in First Hospitalization for Heart Failure and Subsequent Survival Between 1986 and 2003. Circulation [Internet]. 2009 Feb 3 [cited 2019 Jan 21];119(4):515-523. Available from: http://www.ncbi.nlm.nih.gov/pubmed/19153268 PMID: 19153268

5. Laribi S, Aouba A, Nikolaou M, Lassus J, Cohen-Solal A, Plaisance P, Pavillon G, Jois P, Fonarow GC, Jougla E, Mebazaa A, GREAT network. Trends in death attributed to heart failure over the past two decades in Europe. European Journal of Heart Failure [Internet]. 2012 Mar [cited 2019 Jan 21];14(3):234-239. Available from: http://www.ncbi.nlm.nih.gov/pubmed/22237388 PMID: 22237388

6. Askoxylakis V, Thieke C, Pleger ST, Most P, Tanner J, Lindel K, Katus HA, Debus J, Bischof M. Long-term survival of cancer patients compared to heart failure and stroke: A systematic review. BMC Cancer [Internet]. 2010 Dec 22 [cited 2019 Jan 21];10(1):105. Available from: http://www.ncbi.nlm.nih.gov/pubmed/20307299 PMID: 20307299

7. Oz MC, Artrip JH, Burkhoff D. Direct cardiac compression devices. The Journal of heart and lung transplantation : the official publication of the International Society for Heart Transplantation [Internet]. 2002 Oct [cited 2019 Jan 21];21(10):1049-55. Available from: http://www.ncbi.nlm.nih.gov/pubmed/12398868 PMID: 12398868 
8. Kwon MH, Cevasco M, Schmitto JD, Chen FY. Ventricular restraint therapy for heart failure: A review, summary of state of the art, and future directions. The Journal of Thoracic and Cardiovascular Surgery [Internet]. 2012 Oct [cited 2019 Jan 21];144(4):771-777.e1. Available from: http://www.ncbi.nlm.nih.gov/pubmed/22749626 PMID: 22749626

9. Magovern GJ, Simpson KA. Clinical cardiomyoplasty: Review of the ten-year United States experience. The Annals of Thoracic Surgery [Internet]. Elsevier; 1996 Jan 1 [cited 2019 Jan 21];61(1):413-419. Available from: http://linkinghub.elsevier.com/retrieve/pii/000349759501005X

10. Oz MC, Konertz WF, Kleber FX, Mohr FW, Gummert JF, Ostermeyer J, Lass M, Raman J, Acker MA, Smedira N. Global surgical experience with the Acorn cardiac support device. The Journal of Thoracic and Cardiovascular Surgery [Internet]. Elsevier; 2003 Oct 1 [cited 2019 Jan 21];126(4):983-991. Available from: http://linkinghub.elsevier.com/retrieve/pii/S0022522303000497

11. Klodell CT, Aranda JM, McGiffin DC, Rayburn BK, Sun B, Abraham WT, Pae WE, Boehmer JP, Klein H, Huth C. Worldwide surgical experience with the Paracor HeartNet cardiac restraint device. The Journal of Thoracic and Cardiovascular Surgery [Internet]. Elsevier; 2008 Jan 1 [cited 2019 Jan 21];135(1):188-195. Available from: https://linkinghub.elsevier.com/retrieve/pii/S0022522307016406

12. Feindt P, Boeken U, Schipke JD, Litmathe J, Zimmermann N, Gams E. Ventricular constraint in dilated cardiomyopathy: A new, compliant textile mesh exerts prophylactic and therapeutic properties. The Journal of Thoracic and Cardiovascular Surgery [Internet]. Mosby; 2005 Oct 1 [cited 2019 Jan 21];130(4):1107.e11107.e11. Available from: https://www.sciencedirect.com/science/article/pii/S0022522305006872

13. Anstadt MP, Bartlett RL, Malone JP, Brown GR, Martin S, Nolan DJ, Oberheu KH, Anstadt GL. Direct mechanical ventricular actuation for cardiac arrest in humans. A clinical feasibility trial. Chest [Internet]. 1991 Jul [cited 2019 Jan 21];100(1):86-92. Available from: http://www.ncbi.nlm.nih.gov/pubmed/1905620 PMID: 1905620

14. Cheng A, Nguyen TC, Malinowski M, Langer F, Liang D, Daughters GT, Ingels NB, Miller DC. Passive Ventricular Constraint Prevents Transmural Shear Strain Progression in Left Ventricle Remodeling. Circulation [Internet]. 2006 Jul 4 [cited 2019 Jan 21];114(1_suppl):I-79-I-86. Available from: http://www.ncbi.nlm.nih.gov/pubmed/16820650 PMID: 16820650

15. Magovern JA, Teekell???Taylor L, Mankad S, Dasika U, McGregor W, Biederman RWW, Yamrozik J, Trumble DR. Effect of a Flexible Ventricular Restraint Device on Cardiac Remodeling after Acute Myocardial Infarction. ASAIO Journal [Internet]. 2006 Mar [cited 2019 Jan 21];52(2):196-200. Available from: http://www.ncbi.nlm.nih.gov/pubmed/16557108 PMID: 16557108

16. Nawaz W, Khan FU, Khan MZ, Gang W, Yang M, Liao X, Zhang L, Ihsan AU, Khan A, Han L, Zhou $\mathrm{X}$. Exo-organoplasty interventions: A brief review of past, present and future directions for advance heart failure management. Biomedicine and Pharmacotherapy [Internet]. Elsevier Masson SAS; 2017;88:162-172. Available from: http://dx.doi.org/10.1016/j.biopha.2017.01.048

17. Bernik DL. Silicon based materials for drug delivery devices and implants. Recent patents on nanotechnology [Internet]. 2007 [cited 2019 Jan 21];1(3):186-92. Available from: http://www.ncbi.nlm.nih.gov/pubmed/19076032 PMID: 19076032

18. Joung Y-H. Development of implantable medical devices: from an engineering perspective. International neurourology journal [Internet]. 2013 Sep [cited 2019 Jan 21];17(3):98-106. Available from: http://einj.org/journal/view.php?id=10.5213/inj.2013.17.3.98 PMID: 24143287

19. Yasmeen S, Liao X, Khan FU, Ihsan AU, Li X, Li C, Chen D, Yu F, Wang Z, Sembatya KR, Mikrani R, Zhou X. A novel approach to devise the therapy for ventricular fibrillation by epicardial delivery of lidocaine using active hydraulic ventricular attaching support system: An experimental study in rats. Journal of Biomedical Materials Research Part B: Applied Biomaterials [Internet]. John Wiley \& Sons, Ltd; 2018 Oct 27 [cited 2019 Jan 22]; Available from: http://doi.wiley.com/10.1002/jbm.b.34265 
20. Naveed M, Wenhua L, Gang W, Mohammad IS, Abbas M, Liao X, Yang M, Zhang L, Liu X, Qi X, Chen Y, Jiadi L, Ye L, Zhijie W, Ding CD, Feng Y, Xiaohui Z. A novel ventricular restraint device (ASD) repetitively deliver Salvia miltiorrhiza to epicardium have good curative effects in heart failure management. Biomedicine \& Pharmacotherapy [Internet]. 2017 Nov [cited 2019 Jan 21];95:701-710. Available from: https://linkinghub.elsevier.com/retrieve/pii/S0753332217318619

21. Active hydraulic ventricular attaching support system. 2010 Apr 30 [cited 2019 Jan 21]; Available from: https://patents.google.com/patent/WO2010127553A1/en

22. Srivastava A, Sood A, Joy PS, Mandal S, Panwar R, Ravichandran S, Sarangi S, Woodcock J. Principles of physics in surgery: the laws of mechanics and vectors physics for surgeons-part 2. The Indian journal of surgery [Internet]. Springer; 2010 Oct [cited 2019 Jan 21];72(5):355-61. Available from: http://www.ncbi.nlm.nih.gov/pubmed/21966132 PMID: 21966132

23. Cohn WE, Timms DL, Frazier OH. Total artificial hearts: past, present and future. Nature Reviews Cardiology [Internet]. 2015 Oct 2 [cited 2019 Jan 21];12(10):609-617. Available from: http://www.ncbi.nlm.nih.gov/pubmed/26031698 PMID: 26031698

24. Adhyapak SM, Parachuri VR. Architecture of the left ventricle: insights for optimal surgical ventricular restoration. Heart Failure Reviews [Internet]. 2010 Jan 16 [cited 2019 Jan 21];15(1):73-83. Available from: http://www.ncbi.nlm.nih.gov/pubmed/19757029 PMID: 19757029

25. Chew PH, Yin FC, Zeger SL. Biaxial stress-strain properties of canine pericardium. Journal of molecular and cellular cardiology [Internet]. Academic Press Inc.; 1986 Jun [cited 2019 Jan 21];18(6):567-78. Available from: http://www.ncbi.nlm.nih.gov/pubmed/3735439 PMID: 3735439

26. Nazario Leao R, Marques da Silva P. Diastolic dysfunction in hypertension. Hipertension y Riesgo Vascular [Internet]. Elsevier; 2017 Jul 1 [cited 2019 Jan 21];34(3):128-139. Available from: https://linkinghub.elsevier.com/retrieve/pii/S1889183717300016

27. Goldstein S, Ali AS, Sabbah H. Ventricular remodeling. Mechanisms and prevention. Cardiology clinics [Internet]. Elsevier; 1998 Nov 1 [cited 2019 Jan 21];16(4):623-32, vii-viii. Available from: http://www.ncbi.nlm.nih.gov/pubmed/9891592 PMID: 9891592

28. Chrastina A, Pokreisz P, Schnitzer JE. Experimental model of transthoracic, vascular-targeted, photodynamically induced myocardial infarction. American journal of physiology Heart and circulatory physiology [Internet]. American Physiological Society; 2014 Jan 15 [cited 2019 Jan 21];306(2):H270-8. Available from: http://www.ncbi.nlm.nih.gov/pubmed/24213611 PMID: 24213611

29. Konopelski P, Ufnal M. Electrocardiography in rats: a comparison to human. Physiological research [Internet]. 2016 Nov 23 [cited 2019 Jan 21];65(5):717-725. Available from: http://www.ncbi.nlm.nih.gov/pubmed/27429108 PMID: 27429108

30. Dragojevic-Simic VM, Dobric SLJ, Bokonjic DR, Vucinic ZM, Sinovec SM, Jacevic VM, Dogovic NP. Amifostine protection against doxorubicin cardiotoxicity in rats. Anti-cancer drugs [Internet]. 2004 Feb [cited 2019 Jan 21];15(2):169-78. Available from: http://www.ncbi.nlm.nih.gov/pubmed/15075674 PMID: 15075674

31. Malatesta M. Histological and Histochemical Methods - Theory and practice. European Journal of Histochemistry [Internet]. PAGEPress; 2016 Feb 29 [cited 2019 Jan 21];60(1). Available from: http://www.ejh.it/index.php/ejh/article/view/2639

32. Bialik S, Geenen DL, Sasson IE, Cheng R, Horner JW, Evans SM, Lord EM, Koch CJ, Kitsis RN. Myocyte apoptosis during acute myocardial infarction in the mouse localizes to hypoxic regions but occurs independently of p53. The Journal of clinical investigation [Internet]. American Society for Clinical Investigation; 1997 Sep 15 [cited 2019 Jan 21];100(6):1363-72. Available from: http://www.ncbi.nlm.nih.gov/pubmed/9294101 PMID: 9294101 
33. Travers JG, Kamal FA, Robbins J, Yutzey KE, Blaxall BC. Cardiac Fibrosis: The Fibroblast Awakens. Circulation research [Internet]. NIH Public Access; 2016 Mar 18 [cited 2019 Jan 21];118(6):1021-40. Available from: http://www.ncbi.nlm.nih.gov/pubmed/26987915 PMID: 26987915

34. Orogo AM, Gustafsson AB. Cell death in the myocardium: My heart won't go on. IUBMB Life [Internet]. 2013 Aug [cited 2019 Jan 21];65(8):651-656. Available from: http://www.ncbi.nlm.nih.gov/pubmed/23824949 PMID: 23824949

35. Angeli FS, Shapiro M, Amabile N, Orcino G, Smith CS, Tacy T, Boyle AJ, Chatterjee K, Glantz SA, Grossman W, Yeghiazarians Y. Left ventricular remodeling after myocardial infarction: characterization of a swine model on beta-blocker therapy. Comparative medicine [Internet]. 2009 Jun [cited 2019 Jan 21];59(3):272-9. Available from: http://www.ncbi.nlm.nih.gov/pubmed/19619418 PMID: 19619418

36. Bauer JA, Fung HL. Differential hemodynamic effects and tolerance properties of nitroglycerin and an S-nitrosothiol in experimental heart failure. Journal of Pharmacology and Experimental Therapeutics. 1991;256(1).

37. Pourmoghaddas M, Sanei H, Tavassoli A, Shojaei M. Estimation of left ventricular end diastolic pressure (lvedp) in patients with ischemic heart disease by echocardiography and compare it with the results of cardiac catheterization. ARYA atherosclerosis [Internet]. Farzanegan Radandish Co.; 2011 [cited 2019 Jan 21];7(1):1-6. Available from: http://www.ncbi.nlm.nih.gov/pubmed/22577437 PMID: 22577437

38. Chen T, Li J, Liu L, Fan L, Li X, Wang Y, Abraham N, Cao J. Effects of Heme Oxygenase-1 Upregulation on Blood Pressure and Cardiac Function in an Animal Model of Hypertensive Myocardial Infarction. International Journal of Molecular Sciences [Internet]. 2013 Jan 28 [cited 2019 Jan 21];14(2):2684-2706. Available from: http://www.ncbi.nlm.nih.gov/pubmed/23358254 PMID: 23358254

39. Weisfeldt ML, Scully HE, Frederiksen J, Rubenstein JJ, Pohost GM, Beierholm E, Bello AG, Daggett WM. Hemodynamic determinants of maximum negative dP-dt and periods of diastole. The American journal of physiology [Internet]. 1974 Sep [cited 2019 Jan 21];227(3):613-21. Available from: http://www.ncbi.nlm.nih.gov/pubmed/4413651 PMID: 4413651

40. Kinnunen P, Vuolteenaho O, Ruskoaho H. Mechanisms of atrial and brain natriuretic peptide release from rat ventricular myocardium: effect of stretching. Endocrinology [Internet]. Oxford University Press; 1993 May 1 [cited 2019 Jan 21];132(5):1961-1970. Available from: https://academic.oup.com/endo/articlelookup/doi/10.1210/endo.132.5.8477647

41. Muthuramu I, Lox M, Jacobs F. De Geest, B. Permanent Ligation of the Left Anterior Descending Coronary Artery in Mice: A Model of Post-myocardial Infarction Remodelling and Heart Failure. J Vis Exp [Internet]. 2014 [cited 2019 Jan 21];(94):52206. Available from: www.jove.comurl:http://www.jove.com/video/52206http://www.jove.com/video/52206/

42. $\mathrm{Oz}$ MC, Konertz WF, Raman J, Kleber FX. Reverse remodeling of the failing ventricle: surgical intervention with the Acorn Cardiac Support Device. Congestive heart failure (Greenwich, Conn) [Internet]. 2004 [cited 2019 Jan 21];10(2):96-104; discussion 105. Available from: http://www.ncbi.nlm.nih.gov/pubmed/15073455 PMID: 15073455

43. Kung RT, Rosenberg M. Heart booster: a pericardial support device. The Annals of thoracic surgery [Internet]. 1999 Aug [cited 2019 Jan 22];68(2):764-7. Available from: http://www.ncbi.nlm.nih.gov/pubmed/10475485 PMID: 10475485

44. Ruder C, Haase T, Krost A, Langwieser N, Peter J, Kamann S, Zohlnhofer D. Combinatorial GCSF/AMD3100 Treatment in Cardiac Repair after Myocardial Infarction. Goumans MJ, editor. PLoS ONE [Internet]. Public Library of Science; 2014 Aug 14 [cited 2019 Jan 21];9(8):e104644. Available from: http://dx.plos.org/10.1371/journal.pone.0104644

Figure Legend 
Fig. 1 Laplace law explains the dilated ventricles mechanism and provides a framework for ventricle remodeling. ( $\mathrm{T}$ ) is the dilated heart which is directly proportional to left ventricular end diastolic pressure (LVEDP) (P) and radius chamber (R), inversely by wall thickness. Laplace law explains the concept of ASD effect on ventricle remodeling. The relationship between transmural pressure (Ptm) and LVEDP is explained by an equation as shown above. (a) Cross-sectional view of ASD covering both ventricles from base to apex. (b) ASD overview off the epicardium. The two extended tubes are subcutaneously channeled outside of the body and connected to a medical device to load and release fluid (c) View of ASD tubes interconnected with each other.

Fig.2 Functional characteristics of ASD device. (a) Pressure and (b) flow generated by ASD as a function of drive pressure respectively for a flow of $6.6 \mathrm{~L} / \mathrm{min}$ and an after-load of $120 \mathrm{mmHg}$. Calculations are shown as a solid curve. (c) Ball burst test of ASD, a pressure is given by pressing the ball at the center of ASD fixed in a circular fixture. ASD undergo multiaxial expansion by the pressure of the ball. (d) Uniaxial circumferential and longitudinal curve. A multiaxial curve compliance curves are plotted for comparison

Fig.3 Electrocardiographic exploration of all rats' groups at various time periods. ECG contains a P-wave, followed by the QRS-complex and the T-wave. All parameters were recorded in a milliseconds

Fig.4 (a) Masson's trichrome-stained section of rats' heart in various groups by a photonic microscope (Original magnifications $\mathrm{x} 4$ ) revealing a segment of the heart fibers enclosed in collagen (blue) and overlying the myocardium (red). (b) Evaluation of fibrosis of heart tissues acquired from different treatment groups, $\mathrm{n}=3$, Where, ${ }^{*} \mathrm{p}<0.05,{ }^{* *} \mathrm{p}<0.01,{ }^{* * *} \mathrm{p}<0.001$, scale bar $100 \mu \mathrm{m}$.

Fig.5 Hemodynamic parameters represented as mean \pm SEM ( $n=6)$ (a) LVSP (b) LVEDP (c) dp/dtmax (d) $-\mathrm{dp} / \mathrm{dtmax}, \mathrm{nsp}=$ no significance; ${ }^{* *} \mathrm{p}<0.01 ;{ }^{* * *} \mathrm{p}<0.001$ vs. Control

Fig.6 (a) The BNP results formulated as mean $\pm \mathrm{SD}$, (b) The heart rates of the control and treatment groups; HF, CSD+HF, ASD+HF groups. $\mathrm{n}=3$

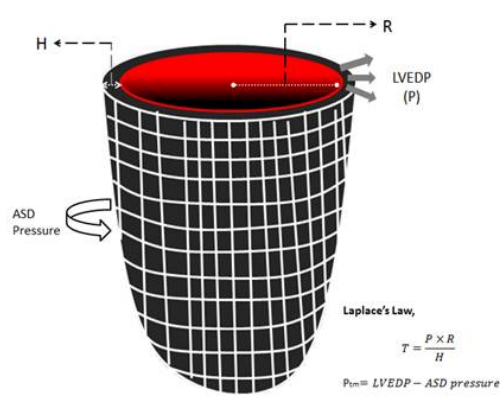

a

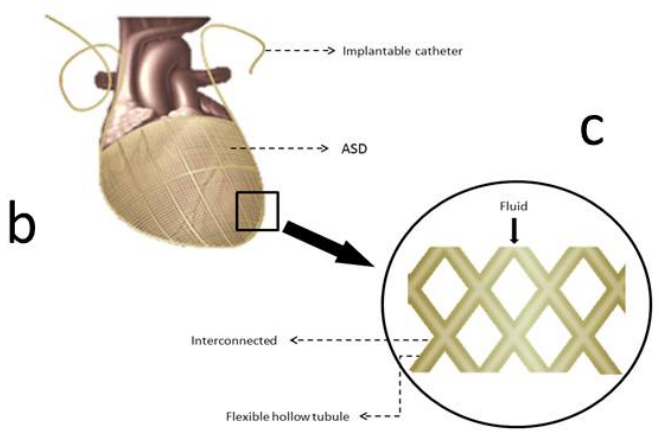


a
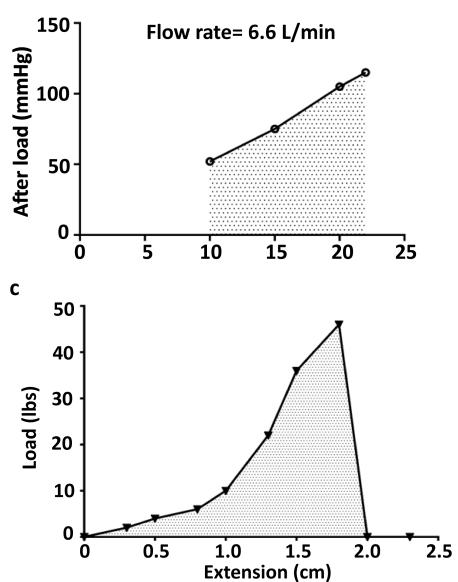

b
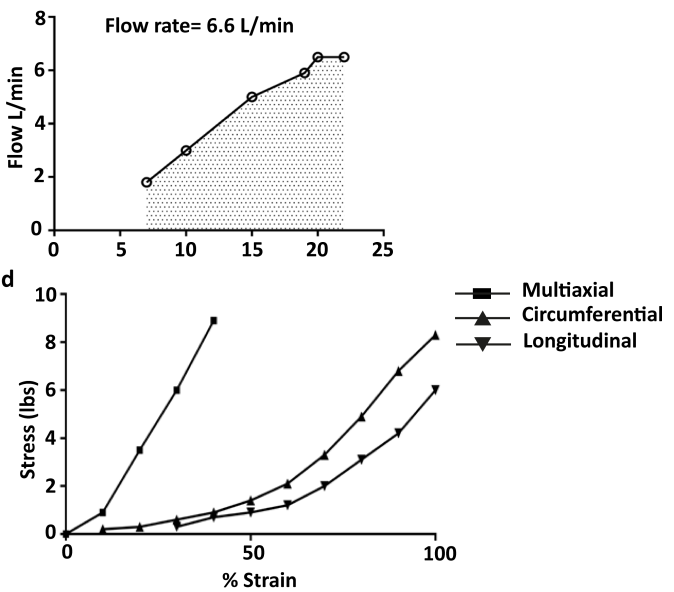

Time
Group

Control
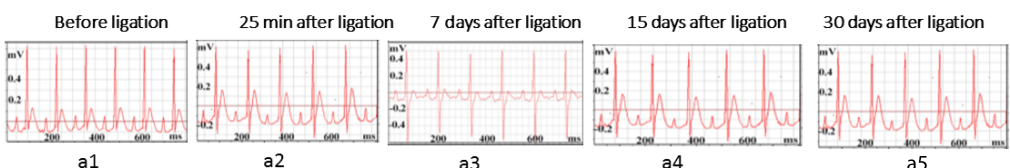

HF
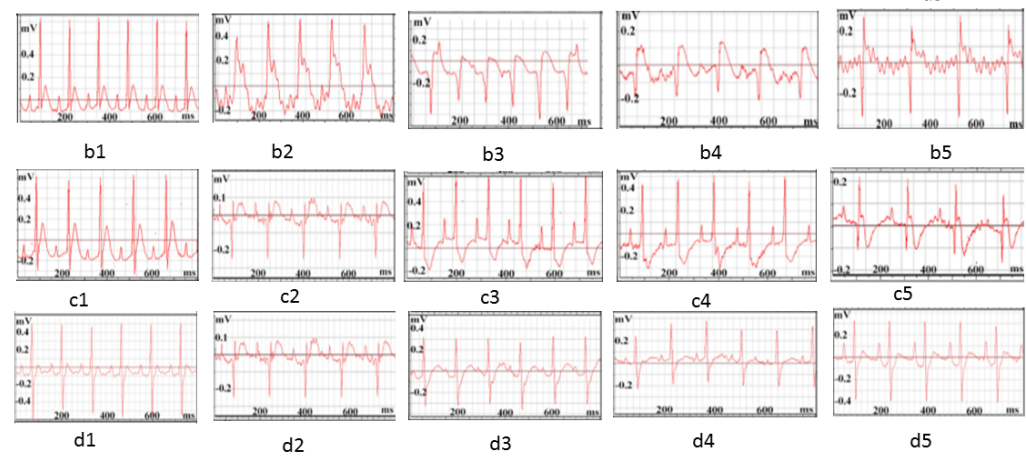

d3

b

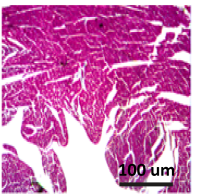

Control

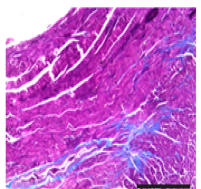

HF+CSD

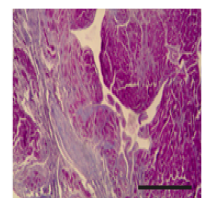

HF

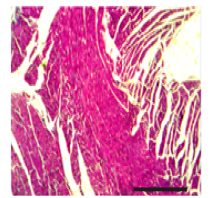

HF+ASD

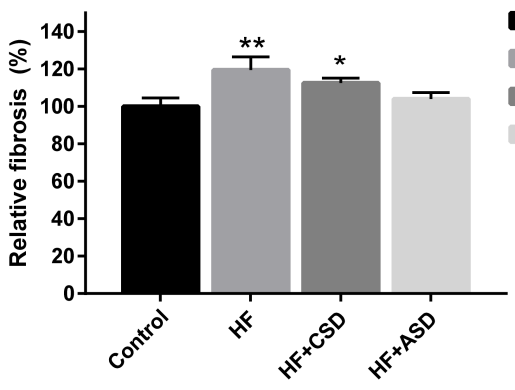

Control

1. HF

DF+CSD

HF+ASD 

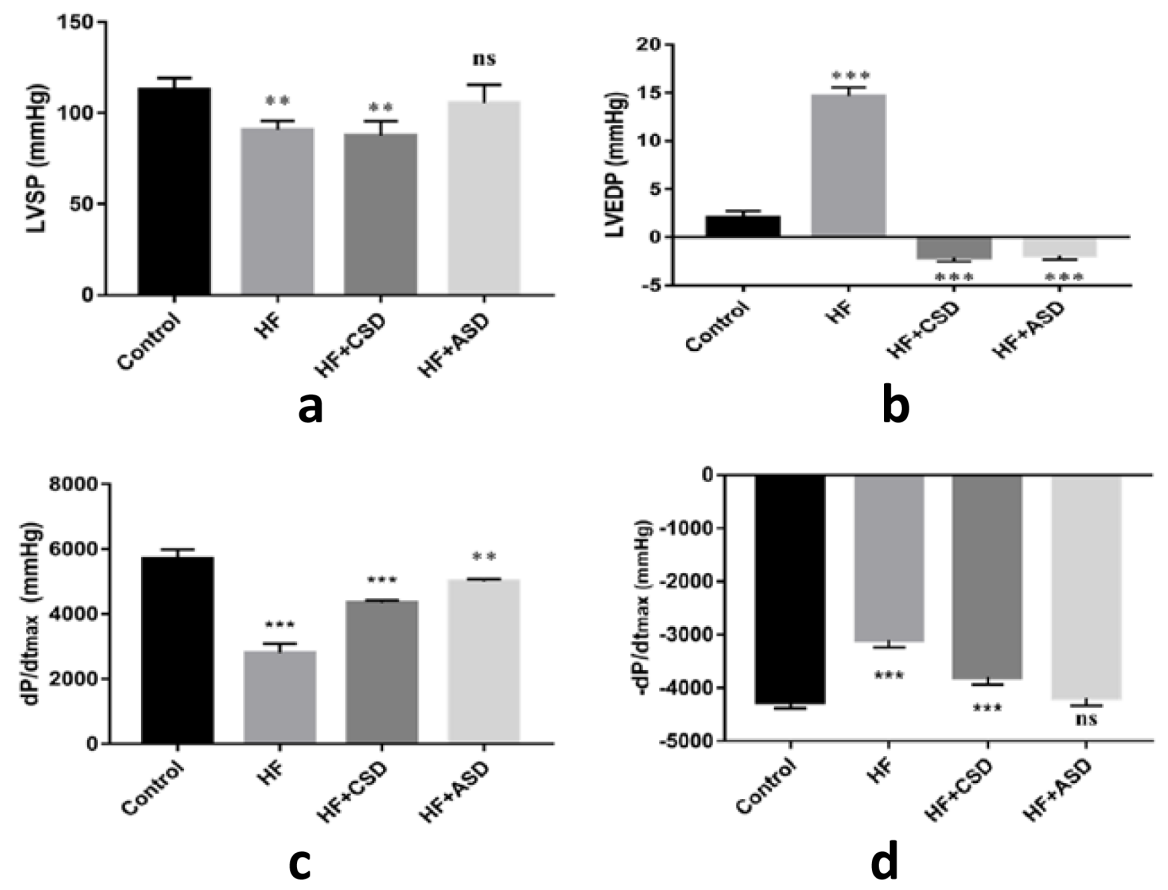

a

b
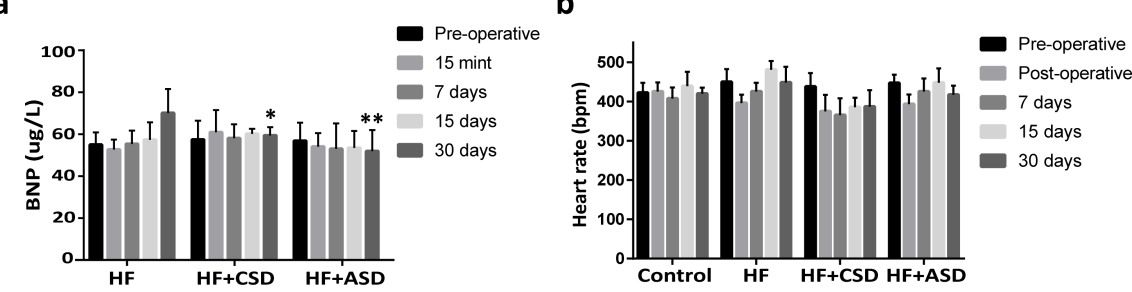